\title{
Deep level transient spectroscopic study of neutron-irradiated n-type $6 \mathrm{H}-\mathrm{SiC}$
}

\author{
X. D. Chen, a) S. Fung, C. C. Ling, and C. D. Beling \\ Department of Physics, The University of Hong Kong, Pokfulam Road, Hong Kong, \\ People's Republic of China \\ M. Gong ${ }^{\text {b) }}$ \\ Department of Physics, Sichuan University, Chengdu, Sichuan 610064, People's Republic of China
}

(Received 20 March 2003; accepted 12 June 2003)

\begin{abstract}
Deep level transient spectroscopy has been employed to study the deep level defects introduced in $n$-type $6 \mathrm{H}-\mathrm{SiC}$ after neutron irradiation. Deep levels situated at $E_{C}-0.23, E_{C}-0.36 / 0.44, E_{C}$ -0.50 , and $E_{C}-0.62 / 0.68 \mathrm{eV}$ have been detected in the temperature range of $100-450 \mathrm{~K}$, which have been identified with the previously reported deep levels $E D 1, E_{1} / E_{2}, E_{i}$, and $Z_{1} / Z_{2}$, respectively. Thermal annealing studies of these deep levels reveal that $E D 1$ and $E_{i}$ anneal at a temperature below $350{ }^{\circ} \mathrm{C}$, the $Z_{1} / Z_{2}$ levels anneal out at $900{ }^{\circ} \mathrm{C}$, while the intensity of the $E_{1} / E_{2}$ peaks is increased with annealing temperature, reaching a maximum at about $500-750{ }^{\circ} \mathrm{C}$, and finally annealing out at $1400^{\circ} \mathrm{C}$. The possible nature of the deep levels $E D 1, E_{1} / E_{2}, E_{i}$, and $Z_{1} / Z_{2}$ are discussed in the context of their annealing behavior. Upon further annealing at $1600{ }^{\circ} \mathrm{C}$, four deep levels labeled $N E 1$ at $E_{C}-0.44 \mathrm{eV}, N E 2 E_{C}-0.53 \mathrm{eV}, N E 3 E_{C}-0.64 \mathrm{eV}$, and $N E 4 E_{C}$ $-0.68 \mathrm{eV}$ are produced. Evidence is given that these levels are different in their origin to $E_{1} / E_{2}$ and $Z_{1} / Z_{2}$. (C) 2003 American Institute of Physics. [DOI: 10.1063/1.1598629]
\end{abstract}

\section{INTRODUCTION}

Silicon carbide $(\mathrm{SiC})$ is a wide band-gap semiconductor material having unique physical and electronic properties for high-temperature, high-power, and high-frequency electronic device applications. ${ }^{1}$ In modern $\mathrm{SiC}$ device technology, electron irradiation and ion implantation are usually employed for the purposes of carrier lifetime control and creating doped layers. It is always found that irradiation-induced defects remain in the operating area of the device even after the annealing procedure. ${ }^{2-4}$ In past years, deep level defects induced by particle irradiation or ion implantation in $\mathrm{SiC}$ have been extensively studied by capacitance transient techniques such as deep level transient spectroscopy (DLTS). ${ }^{2-10}$ Deep levels at $E_{C}-0.6-0.7 \mathrm{eV}$ (termed $Z_{1} / Z_{2}$ ) have been reported to be persistent even after thermal annealing at $1700{ }^{\circ} \mathrm{C}$ and are generated either by irradiation with highenergy electrons or by implantation of ions. ${ }^{2-4}$ However, recent DLTS studies of the thermal annealing behavior of the $Z_{1} / Z_{2}$ levels have shown that these levels almost disappear with postirradiation annealing temperatures below $1000{ }^{\circ} \mathrm{C} .{ }^{6,7}$ Another important grouping of deep levels are those found at $E_{C}-0.36$ and $E_{C}-0.44 \mathrm{eV}$ (usually termed $\left.E_{1} / E_{2}\right)$. These peaks are normally seen in the DLTS spectra of electron-irradiated $6 \mathrm{H}-\mathrm{SiC} .^{4-8}$ However, in the studies of He implanted ${ }^{4}$ and deuterium implanted ${ }^{7} n$-type $6 \mathrm{H}-\mathrm{SiC}$, $E_{1} / E_{2}$ are not clearly detectable in as-irradiated samples, but they become so after thermal annealings of $430{ }^{\circ} \mathrm{C}^{4}$ and

\footnotetext{
a) Author to whom correspondence should be addressed; electronic-mail: chenxa@hkusua.hku.hk

b) Also at: International Center for Materials Physics, Chinese Academy of Science, Shenyang, 110015, People's Republic of China.
}

$800{ }^{\circ} \mathrm{C},{ }^{7}$ respectively. $E_{1} / E_{2}$ appears to be the most stable of defect centers, only annealing out at temperatures above $1200{ }^{\circ} \mathrm{C} .^{4-8}$ In addition to $Z_{1} / Z_{2}$ and $E_{1} / E_{2}$ there is usually also seen in electron-irradiated material a less prominent peak labeled $E_{i}$ at $\sim E_{C}-0.50 \mathrm{eV} .^{4-8}$ The atomic structures of the $E_{1} / E_{2}, Z_{1} / Z_{2}$, and $E_{i}$ levels have attracted a great deal of discussion but have not yet been unambiguously clarified.

Nuclear transmutation doping (NTD) has been shown to be a promising technique for doping the material with phosphorus $(\mathrm{P})$ donor. ${ }^{11,12}$ This technology is based on the capture of a thermal neutron of ${ }^{30} \mathrm{Si}$ by the reaction $\left[{ }^{30} \mathrm{Si}(n, \gamma)-{ }^{31} \mathrm{Si}\right]$ and the subsequent $\beta^{-}$decay which forms the dopant ${ }^{31} \mathrm{P}$. However, the defects introduced by $(n, \gamma)$ recoil and by fast neutrons can act as compensation centers and thus influence the electrical properties of the material. ${ }^{13}$ Thus, there is a need to identify and to understand the defects introduced by neutron irradiation. Neutron irradiation-induced deep levels labeled $H 1, H 2, H 3$, and $E 2$ in $3 \mathrm{C}-\mathrm{SiC}$ have been reported by Nagesh et al. ${ }^{13,14}$ In the case of neutron irradiated $6 \mathrm{H}-$ $\mathrm{SiC}$, it was reported that neutron-irradiation defects were generated homogeneously throughout the crystal. ${ }^{15}$ Defect centers introduced by neutron radiation have been investigated using electron paramagnetic resonance (EPR), ${ }^{16}$ positron annihilation spectroscopy (PAS), ${ }^{17}$ magnetic circular dichroism of the absorption (MCDA) and MCDA detected EPR (MCDA-EPR), ${ }^{18}$ but this kind of study using DLTS is still lacking. DLTS is one of the most direct techniques for the determination of energy states of deep level defects. In the present report, deep level defects formed in $n$-type $6 \mathrm{H}-$ $\mathrm{SiC}$ irradiated with different doses of neutron have been studied by the DLTS technique. The nature of the observed 


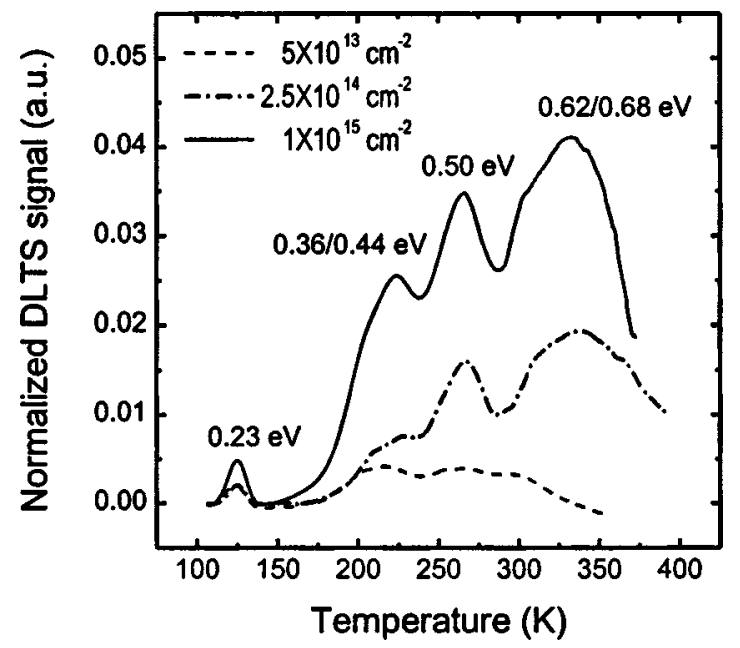

FIG. 1. Normalized DLTS spectra for $n$-type $6 \mathrm{H}-\mathrm{SiC}$ irradiated with neutron to doses of $5 \times 10^{13} \mathrm{n} / \mathrm{cm}^{2}, 2.5 \times 10^{14} \mathrm{n} / \mathrm{cm}^{2}$, and $1 \times 10^{15} \mathrm{n} / \mathrm{cm}^{2}$. A rate window of $6.82 \mathrm{~ms}$ was used in the measurements.

defect levels has been discussed according to their observed thermal annealing behavior.

\section{EXPERIMENT}

The starting $n$-type $6 \mathrm{H}-\mathrm{SiC}$ samples used in this experiment were purchased from CREE Research Inc. in the form of a 5- $\mu \mathrm{m}$-thick nitrogen doped (0001) oriented epitaxial layer grown on $n^{+}$-type $6 \mathrm{H}-\mathrm{SiC}$ substrate. The nitrogen donor concentrations were $1 \times 10^{16}$ and $8 \times 10^{17} \mathrm{~cm}^{-3}$ in the epitaxial layer and the substrate, respectively. The samples were rinsed in boiling acetone, ethanol, and de-ionized water, and were then chemically treated in $10 \%$ hydrofluoric acid solution to remove the oxidation layer. Large area ohmic contacts were made by evaporating $\mathrm{Al}$ on the backside of the samples followed by a 5 min annealing process at $900{ }^{\circ} \mathrm{C}$ in pure nitrogen gas.

The samples were irradiated with neutrons at room temperature to doses of $5.1 \times 10^{13}, 2.5 \times 10^{14}$, and 1.0 $\times 10^{15} \mathrm{n} / \mathrm{cm}^{2}$, respectively. The flux ratio of fast neutrons to thermal neutrons was around 30\%. Isochronal thermal annealing of the irradiated samples was carried out in an atmosphere of nitrogen gas at temperatures between 100 and

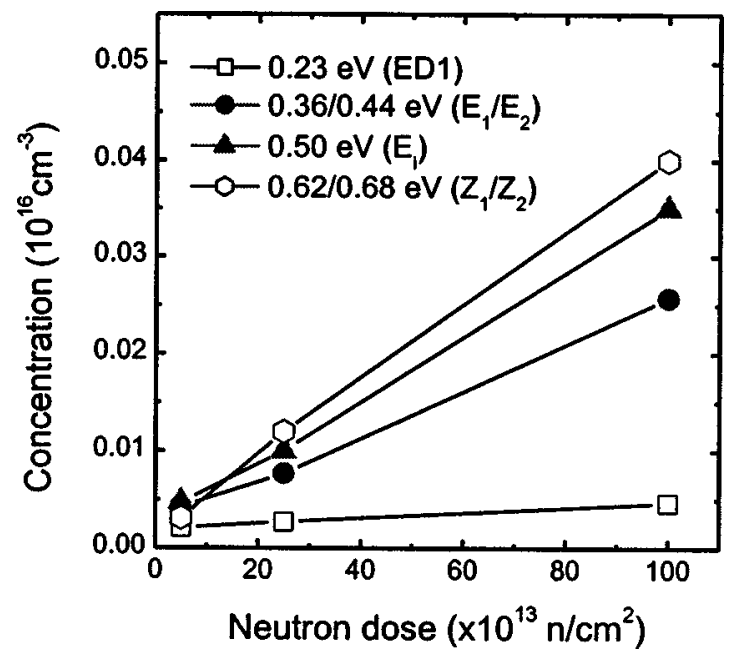

FIG. 2. Concentration of the observed deep levels as a function of the neutron dose for the energy levels $0.23,0.36 / 0.44,0.50$, and $0.62 / 0.68 \mathrm{eV}$. The lines joining the points are only for visual guidance.

$1100{ }^{\circ} \mathrm{C}$ for $30 \mathrm{~min}$. Higher temperature annealing at 1200 , 1400 , and $1600^{\circ} \mathrm{C}$ were performed for $30 \mathrm{~min}$ in pure argon gas. Schottky contacts for DLTS measurement were prepared by depositing gold dots of $0.6 \mathrm{~mm}$ diameter by thermal evaporation on the surface of epitaxial layer.

The DLTS system used in the present work has been described elsewhere. ${ }^{19}$ These measurements were carried out by applying a reverse bias of $V_{r}=-6 \mathrm{~V}$, with a forward filling pulse of $V_{p}=6 \mathrm{~V}$. DLTS spectra were taken in the range of $100-450 \mathrm{~K}$. The trap energy levels and capture cross sections were determined from the slope and the intercept of the Arrhenius plots using the equation $e_{n} / T^{2}$ $=\gamma_{n} \sigma_{n} \exp \left\{-\left(E_{C}-E_{t}\right) / k T\right\}$ where $e_{n}$ is the rate of emission from the trap to the conduction band, $\gamma_{n}$ is a constant comprised of the temperature independent terms of the density of states and electron thermal velocity, $\sigma_{n}$ is the capture cross section, and $\left(E_{C}-E_{t}\right)$ is the deep level activation energy. The trap concentration was evaluated from the peak heights of the DLTS signal using the procedure described in Ref. 20. In the calculations, the defect capture cross sections were assumed to be temperature independent.

TABLE I. Energy levels $\left(E_{C}-E_{t}\right)$, capture cross sections $\left(\sigma_{n}\right)$, and production rates of the deep levels determined using the DLTS data of the neutron irradiated $n$-type $6 \mathrm{H}-\mathrm{SiC}$ samples.

\begin{tabular}{|c|c|c|c|c|c|}
\hline \multicolumn{3}{|c|}{$\begin{array}{l}\text { Present DLTS study on neutron } \\
\text { irradiated samples }\end{array}$} & \multicolumn{3}{|c|}{$\begin{array}{l}\text { Previously reported deep level defects in } n \text {-type } 6 \mathrm{H}-\mathrm{SiC} \\
\text { after irradiation or implantation of particles }\end{array}$} \\
\hline $\begin{array}{l}E_{C}-E_{t} \\
(\mathrm{eV})\end{array}$ & $\begin{array}{c}\sigma_{n} \\
\left(\mathrm{~cm}^{2}\right)\end{array}$ & $\begin{array}{l}\text { Production } \\
\text { rate } \\
\left(\mathrm{cm}^{-1}\right)\end{array}$ & Electron irradiated & $\begin{array}{l}\text { Proton and deuterium } \\
\text { irradiated }\end{array}$ & He implanted \\
\hline 0.23 & $\sim 10^{-15}$ & $\sim 0.02$ & $E D 1(0.27 \mathrm{eV})[$ Ref. 6$]$ & & \\
\hline $0.36 / 0.44$ & $\sim 10^{-14}$ & $\sim 0.4 / 0.5$ & $\begin{array}{c}E_{1} / E_{2}(0.38 / 0.44 \mathrm{eV}), \\
\sigma \sim 10^{-14} \mathrm{~cm}^{-2} \text { [Ref. 5] }\end{array}$ & $\begin{array}{c}0.34 / 0.41 \mathrm{eV}, \text { [Ref. 7] } \\
0.36 / 0.40 \mathrm{eV} \\
\sigma \sim 10^{-15} \mathrm{~cm}^{-2} \text { [Ref. 8] }\end{array}$ & $\begin{array}{l}E_{1} / E_{2}(0.39-0.43 \mathrm{eV}) \\
\left.\sigma \sim 10^{-14} \mathrm{~cm}^{-2} \text { [Ref. } 4\right]\end{array}$ \\
\hline 0.50 & $\sim 10^{-15}$ & $\sim 0.7$ & $\begin{array}{c}0.51 \mathrm{eV},[\text { Ref. } 7] \\
E_{i}(0.51 \mathrm{eV}), \sigma \sim 10^{-15} \mathrm{~cm}^{-2}[\text { Ref. } 5]\end{array}$ & $0.51 \mathrm{eV}^{\mathrm{d}}$ & $\begin{array}{l}R D 5(0.43-0.47 \mathrm{eV}) \\
\sigma \sim 10^{-15} \mathrm{~cm}^{-2}[\text { Ref. } 4]\end{array}$ \\
\hline $0.62 / 0.68$ & $\sim 10^{-16}$ & $\sim 0.6 / 0.7$ & $Z_{1} / Z_{2}, \sigma \sim 10^{-16}-10^{-17} \mathrm{~cm}^{-2}$ [Ref. 5] & $\begin{array}{c}0.62 / 0.64 \mathrm{eV},[\text { Ref. } 7] \\
0.7 \mathrm{eV}, \sigma \sim 10^{-15} \mathrm{~cm}^{-2}[\text { Ref. } 8]\end{array}$ & $\begin{array}{c}Z_{1} / Z_{2}(0.65-0.72 / 0.58-0.63 \mathrm{eV}) \\
\left.\sigma \sim 10^{-15}-10^{-14} \mathrm{~cm}^{-2} \text { [Ref. } 4\right]\end{array}$ \\
\hline
\end{tabular}




\section{RESULTS}

Figure 1 shows the DLTS spectra of the as-irradiated $n$-type $6 \mathrm{H}-\mathrm{SiC}$ samples with neutron doses of $5.1 \times 10^{13}$, $2.5 \times 10^{14}$, and $1.0 \times 10^{15} \mathrm{n} / \mathrm{cm}^{2}$, respectively. Six major peaks are observed in these spectra having activation energies of $E_{C}-0.23, E_{C}-0.36, E_{C}-0.44, E_{C}-0.50, E_{C}$ -0.62 , and $E_{C}-0.68 \mathrm{eV}$, the closely spaced $0.36 / 0.44 \mathrm{eV}$ levels, and $0.62 / 0.68 \mathrm{eV}$ levels overlapping with each other to give broad peaks that can only just be decomposed. DLTS measurements performed on un-irradiated Schottky contacted epitaxial layer control samples did not reveal any deep levels with concentration above $\sim 10^{13} \mathrm{~cm}^{-3}$, indicating that all the observed defect levels are neutron induced.

The fluence dependence of the defect concentrations evaluated using the present DLTS data is shown in Fig. 2. As can be seen, the observed deep levels depend proportionally on neutron dose, again indicating that they are neutron irradiation introduced. The energy levels, capture cross sections and introduction rates of the deep levels are summarized in Table I. It was reported by individual groups that in $n$-type $6 \mathrm{H}-\mathrm{SiC}$, deep level defects labeled $E D 1, E_{1} / E_{2}, E_{i}$ (or $R D 5)$ and $Z_{1} / Z_{2}$ are induced by electron irradiation, ${ }^{5-7}$ proton, ${ }^{8}$ deuterium, ${ }^{7}$ or He implantation. ${ }^{4,9,10}$ The activation energies and capture cross sections of these deep level defects as reported by these other workers are also listed in Table I for reference. Good agreement is seen between the parameters of the present neutron irradiation induced defects and those reported from the previous studies. Thus, the present observed deep levels $E_{C}-0.23, E_{C}-0.36 / 0.44, E_{C}$ -0.50 , and $E_{C}-0.62 / 0.68 \mathrm{eV}$ are believed to be the levels $E D 1, E_{1} / E_{2}, E_{i}$ (or $R D 5$ ), and $Z_{1} / Z_{2}$, respectively, and the same nomenclature is retained in this study.

As shown in the DLTS spectrum of the 2.5 $\times 10^{14} \mathrm{n} / \mathrm{cm}^{2}$ dose as-irradiated sample in Fig. 1 , it can be seen that the amplitude ratio of the $E_{1} / E_{2}$ peak to the $E_{i}$ peak is roughly $0.4 / 1$ and referencing the peak height of $E_{1} / E_{2}$ to $Z_{1} / Z_{2}$ gives a similar ratio. These relative intensities are quite different from those reported in the electronirradiated $6 \mathrm{H}-\mathrm{SiC}$ material where one typically finds the $E_{i}$ and $Z_{1} / Z_{2}$ peaks an order of magnitude less in intensity than $E_{1} / E_{2} \cdot{ }^{5-7}$ The increased importance $E_{i}$ and of $Z_{1} / Z_{2}$ peaks in the neutron-irradiated material is consistent with the asirradiated samples being implanted by heavy particles (like deuterium ${ }^{7}$ and $\mathrm{He}^{4,10}$ ).

To investigate the thermal annealing behavior of the observed deep level defects, $100-1600^{\circ} \mathrm{C}$ isochronal annealing was performed on the as-irradiated samples with each of the annealing steps lasting for $30 \mathrm{~min}$. Figure 3 shows some of the typical DLTS spectra of the neutron-irradiated samples annealed at temperatures between 200 and $1400^{\circ} \mathrm{C}$, from which the extinction of the deep levels $E D 1, E_{1} / E_{2}, E_{i}$, and $Z_{1} / Z_{2}$ during the annealing process are clearly seen. Isochronal annealing curves for the normalized DLTS signal intensities of $E D 1, E_{1} / E_{2}, E_{i}$, and $Z_{1} / Z_{2}$ are shown in Fig. 4 from which it may be seen that $E D 1$ and $E_{i}$ both anneal out below $350{ }^{\circ} \mathrm{C}$. On the other hand, the level $E_{1} / E_{2}$ increases with annealing temperature, reaching a maximum at temperature of $\sim 500^{\circ} \mathrm{C}$, thereafter dropping and reaching

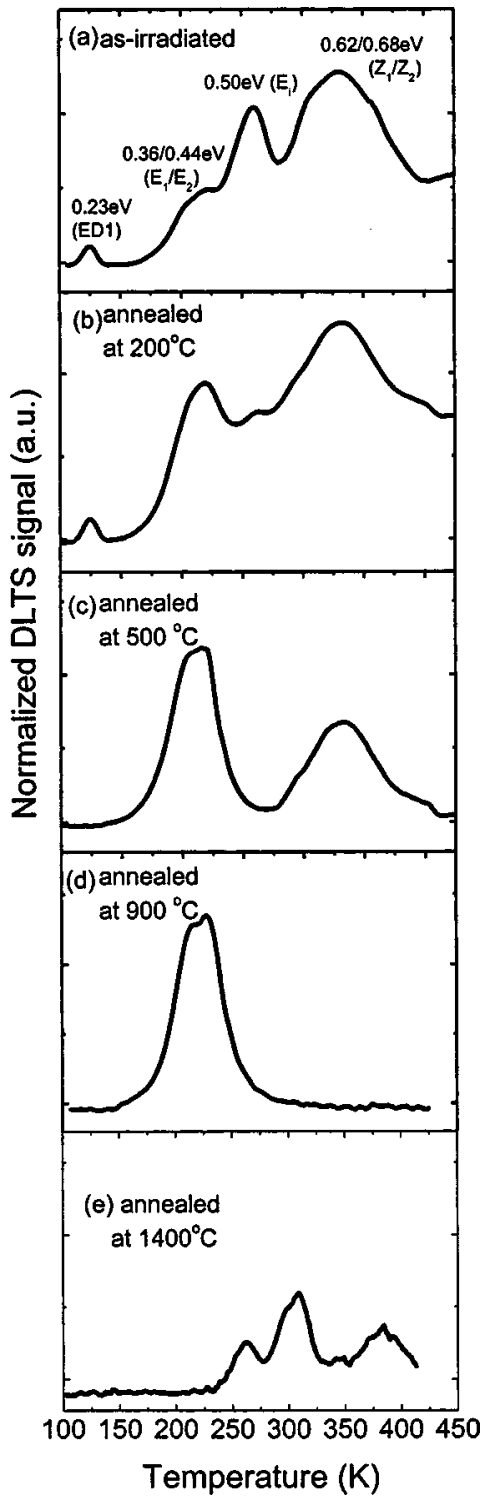

FIG. 3. Normalized DLTS spectra for $n$-type $6 \mathrm{H}-\mathrm{SiC}$ irradiated with neutron to dose $2.5 \times 10^{14} \mathrm{n} / \mathrm{cm}^{2}$ with subsequent annealing at $200^{\circ} \mathrm{C}(\mathrm{b})$, $500{ }^{\circ} \mathrm{C}(\mathrm{c}), 900{ }^{\circ} \mathrm{C}(\mathrm{d})$, and $1400{ }^{\circ} \mathrm{C}(\mathrm{e})$, respectively.

the DLTS signal limit $\left(\sim 10^{12} \mathrm{~cm}^{-3}\right)$ above $1400^{\circ} \mathrm{C}$. For the case of $Z_{1} / Z_{2}$, the intensity decreases slightly with sample annealed up to $500{ }^{\circ} \mathrm{C}$ and then undergoes a drastic decrease at $\sim 750^{\circ} \mathrm{C}$, finally falling below the DLTS signal limit at $900^{\circ} \mathrm{C}$

Annealing at temperatures beyond $1400^{\circ} \mathrm{C}$ produces some interesting results. Figure 5 shows the DLTS spectra of the 500 and the $1600^{\circ} \mathrm{C}$ annealed neutron-irradiated $n$-type $6 \mathrm{H}-\mathrm{SiC}$ samples. A $1600^{\circ} \mathrm{C}$ annealing of un-irradiated control sample was also performed with the corresponding DLTS spectrum also included in Fig. 5. For the neutron irradiated sample, although all the deep levels $E D 1, E_{1} / E_{2}, E_{i}$, and $Z_{1} / Z_{2}$ have already annealed out at the annealing temperature of $1400{ }^{\circ} \mathrm{C}$, four additional DLTS peaks (denoted by $N E 1-N E 4)$ are observed after the $1600{ }^{\circ} \mathrm{C}$ annealing. Arrhenius plots for the $N E 1-N E 4$ deep levels are shown in Fig. 6. The activation energies and capture cross sections of the $N E 1-N E 4$ levels are summarized in Table II. Moreover, 


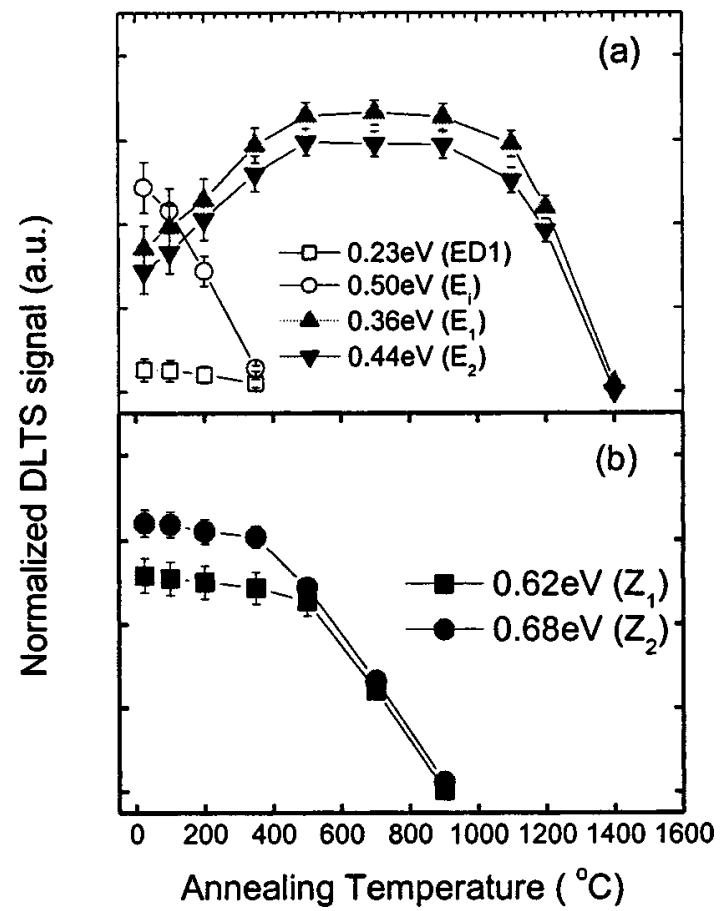

FIG. 4. Peak intensity as a function of annealing temperature for the deep levels (a) $0.23,0.36 / 0.44$, and $0.50 \mathrm{eV}$; and (b) $0.62 / 0.68 \mathrm{eV}$ measured from the sample irradiated with neutron to dose of $2.5 \times 10^{14} \mathrm{n} / \mathrm{cm}^{2}$.

these four peaks can also be seen in the DLTS spectrum of the $1600{ }^{\circ} \mathrm{C}$ annealed nonirradiated sample, although the peak intensities are much lower than those of the $1600^{\circ} \mathrm{C}$ annealed neutron-irradiated sample.

\section{DISCUSSION}

\section{A. ED1 level}

It can be seen in Fig. 1 that the neutron induced level $\left(E_{C}-0.23 \mathrm{eV}\right)$ level is a relatively weak DLTS peak. Its activation energy is close to that of $E D 1\left(E_{C}-0.27 \mathrm{eV}\right)$,

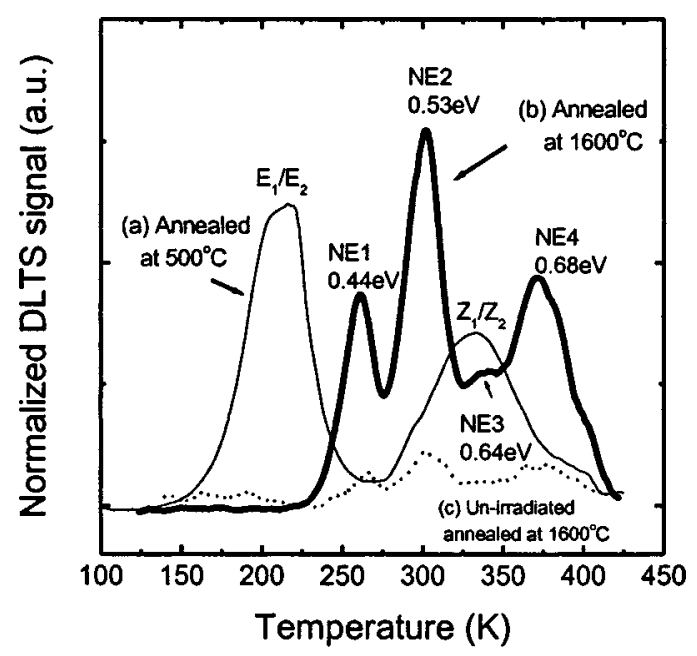

FIG. 5. Normalized DLTS spectra for $n$-type $6 \mathrm{H}-\mathrm{SiC}$ irradiated with neutron to dose $2.5 \times 10^{14} \mathrm{n} / \mathrm{cm}^{2}$ with subsequent annealing at $500{ }^{\circ} \mathrm{C}$ (a), $1600{ }^{\circ} \mathrm{C}(\mathrm{b})$, and un-irradiated control sample with annealing at $1600^{\circ} \mathrm{C}(\mathrm{c})$, respectively. A rate window of $6.82 \mathrm{~ms}$ was used in the measurements.

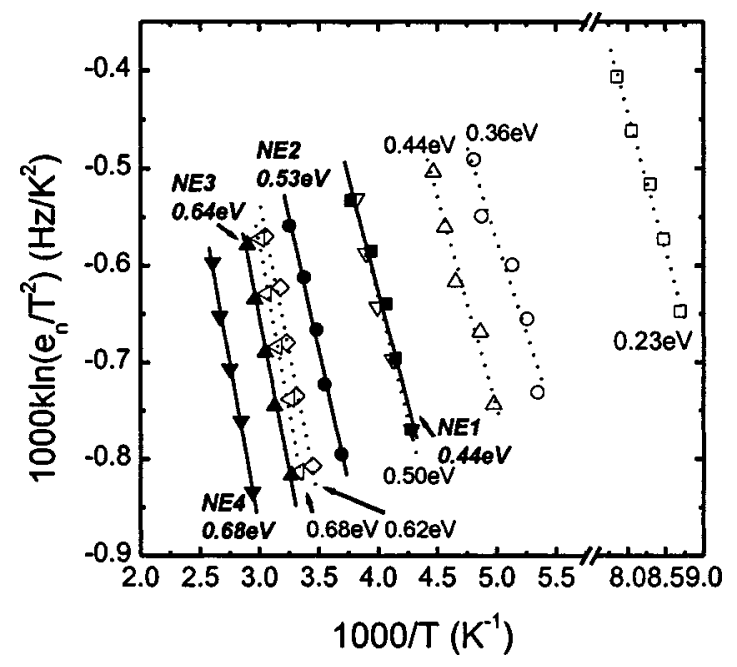

FIG. 6. Arrhenius plots of the emission rates $1000 \mathrm{k} \ln \left(e_{n} / T^{2}\right)$ vs reciprocal temperature for as-neutron-irradiated $n$-type $6 \mathrm{H}-\mathrm{SiC}$ to dose of 2.5 $\times 10^{14} \mathrm{n} / \mathrm{cm}^{2}$ (open scatters and dotted lines) and for irradiated sample with subsequent annealing at $1600{ }^{\circ} \mathrm{C}$ (closed scatters and solid lines), respectively. Here $k$ is the Boltzmann constant and $e_{n}$ is the emission rate corresponding to different rate windows.

which was previously found in electron-irradiated $6 \mathrm{H}-\mathrm{SiC}$ samples. ${ }^{6}$ Similar to the annealing temperature of $E D 1$ $\left(\sim 300^{\circ} \mathrm{C}\right)$, the deep level $E_{C}-0.23 \mathrm{eV}$ also anneals out at a relatively low temperature $\left(<350^{\circ} \mathrm{C}\right)$. Because of its low annealing temperature, Gong et al..$^{6}$ suggested that $E D 1$ was possibly related to an interstitial defect as such sites have a relatively low migration energy.

\section{B. $E_{i}$ level}

The $E_{C}-0.50 \mathrm{eV}$ level in the present neutron-irradiated experiment is very close to the $E_{i}$ deep level found in the electron-irradiated at $E_{C}-0.51 \mathrm{eV}^{5,7}$ and the level $R D 5$ (at $E_{C}-0.5 \mathrm{eV}$ ) found in $\mathrm{He}$ implanted $6 \mathrm{H}-\mathrm{SiC}$ materials. ${ }^{4}$ Aboelfotoh and Doyle ${ }^{7}$ have reported the electronirradiation-induced $E_{C}-0.51 \mathrm{eV}$ level to anneal out below $300^{\circ} \mathrm{C}$ while Dalibor et al. have shown the He implantation induced $R D 5$ to be significantly reduced after a $430{ }^{\circ} \mathrm{C}$ annealing. ${ }^{4}$ In the present neutron irradiated sample, this deep level anneals at about $350{ }^{\circ} \mathrm{C}$. The annealing behavior of the $E_{C}-0.51 \mathrm{eV}$ observed in Aboelfotoh and Doyle's study (and also the $E_{C}-0.50 \mathrm{eV}$ level in the present study) is very similar to that of the $T 5$ center found in Itoh et al.'s EPR study of electron and proton irradiated $p$-type $3 \mathrm{C}-\mathrm{SiC}$, which was attributed to a positively charged carbon vacancy $V_{C}^{+} .{ }^{21}$ The $T 5$ center was found to anneal out $\sim 300^{\circ} \mathrm{C}$. This led that the $E_{i}$ level is suggested to be related to a carbon vacancy. However, in a more recent EPR study, Son, Hai, and Janzén ${ }^{22}$ have identified the EI5 center, which anneals at $500{ }^{\circ} \mathrm{C}$, as a positively charged carbon vacancy $V_{C}^{+}$, an annealing temperature that coincides with the carbon vacancy as seen from positron lifetime measurements. ${ }^{23,24}$ Son and co-workers further argued the $T 5$ is not a $V_{C}^{+}$defect but possibly a $V_{C}+n H(n=1,2)$ complex. ${ }^{22}$ In summary, the evi- 
TABLE II. Energy levels $\left(E_{C}-E_{t}\right)$, capture cross sections $\left(\sigma_{n}\right)$, and concentrations $\left(N_{t}\right)$ of the deep levels determined using the DLTS data of the neutron irradiated $n$-type $6 \mathrm{H}-\mathrm{SiC}$ samples annealed at $1600{ }^{\circ} \mathrm{C}$.

\begin{tabular}{|c|c|c|c|c|}
\hline & $\begin{array}{l}E_{C}-E_{t} \\
(\mathrm{eV})\end{array}$ & $\begin{array}{c}\sigma_{n} \\
\left(\mathrm{~cm}^{-2}\right)\end{array}$ & $\begin{array}{c}N_{t} \\
\left(\mathrm{~cm}^{-3}\right)\end{array}$ & References \\
\hline$N E 1$ & 0.44 & $\sim 10^{-15}$ & $2-5 \times 10^{14}$ & $\begin{array}{l}I D 6 E_{C}-0.40-0.43 \mathrm{eV} \text { (Ref. 4) } \\
B E 2 E_{C}-0.44 \mathrm{eV} \text { (Ref. 29) }\end{array}$ \\
\hline$N E 2$ & 0.53 & $\sim 10^{-15}$ & $4-8 \times 10^{14}$ & $\begin{array}{l}\text { ID } 7 E_{C}-0.50-0.54 \mathrm{eV} \text { (Ref. 4) } \\
B E 3 E_{C}-0.53 \mathrm{eV} \text { (Ref. 29) }\end{array}$ \\
\hline$N E 3$ & 0.64 & $\sim 10^{-16}$ & $1-3 \times 10^{14}$ & \\
\hline$N E 4$ & 0.68 & $\sim 10^{-17}$ & $2-6 \times 10^{14}$ & \\
\hline
\end{tabular}

dence strongly points towards $E_{i}$ being a $V_{C}$ or a $V_{C}$ related complex with the possibility of hydrogen association requiring further investigation.

\section{C. $E_{1} / E_{2}$ levels}

For the case of the $E_{1} / E_{2}\left(E_{C}-0.36 / 0.44 \mathrm{eV}\right)$ level, the introduction rate and thermal annealing behavior observed on the present neutron irradiated $n$-type $6 \mathrm{H}-\mathrm{SiC}$ is markedly different from those observed for electron irradiated samples. ${ }^{5-7}$ As noted while $E_{1} / E_{2}$ are usually the dominant peaks in the DLTS spectra of electron-irradiated $n$-type $6 \mathrm{H}-$ $\mathrm{SiC}$ materials, the relative intensity of $E_{1} / E_{2}$ in the neutronirradiated material is low (see Fig. 1). Speculation that the relative lower intensity of $E_{1} / E_{2}$ in the neutron-irradiated spectrum is due to the effect of the deep level occupancy, which is determined by the Fermi level position, can be ruled out. First, in the present study, the total concentration of observed deep levels which could act as potential compensating centers was at least one order of magnitude smaller than the dopant concentration. Second, the observation of the $E D 1$ level indicates that the Fermi level is at least high enough to populate the level at $E_{C}-0.23 \mathrm{eV}$. Third, the low relative intensity is a general consistency with DLTS spectra seen under heavy particle irradiation. More specifically, the observed $E_{1} / E_{2}$ intensity increases with annealing temperature in the present neutron-irradiated samples becoming dominant at $500{ }^{\circ} \mathrm{C}$ and persisting until annealing temperatures of $1200^{\circ} \mathrm{C}$. The observation of similar increasing and subsequent decreasing behavior, together with a similarly relatively low $E_{1} / E_{2}$ intensity, is also seen in other $n$-type $6 \mathrm{H}-\mathrm{SiC}$ samples irradiated with heavy particles, like $\mathrm{He}$ (Ref. 4) or deuterium. ${ }^{7}$ For $\mathrm{He}$ and deuterium irradiated samples, the $E_{1} / E_{2}$ peak is found to be dominant at the annealing temperatures of 430 and $800{ }^{\circ} \mathrm{C}$, respectively. ${ }^{4,7}$

The microstructure of $E_{1} / E_{2}$ is still not yet confirmed with possible suggestions being the negatively charged carbon vacancy $V_{C},{ }^{7}$ a divacancy $V_{C} V_{\mathrm{Si}},{ }^{6}$ or a complex consisting of a $V_{\mathrm{Si}} \cdot{ }^{25,26}$ Other than these suggestions, one clue to the possible identity of the $E_{1} / E_{2}$ defect comes from the work of Lingner, Greulich-Weber, and Spaeth ${ }^{18}$ who have studied neutron irradiated $n$-type $6 \mathrm{H}-\mathrm{SiC}$ sample with electron paramagnetic resonance (EPR), magnetic circular dichroism of the absorption (MCDA) and MCDA detected EPR (MCDA-EPR). P6/P7 centers were detected only in neutron irradiated samples after a $600{ }^{\circ} \mathrm{C}$ annealing, but not in the un-irradiated or the as-irradiated samples. The $P 6 / P 7$ signal was found to persist at $1200{ }^{\circ} \mathrm{C}$ annealing. Theoretical modeling performed by these authors showed the carbon antisite carbon vacancy $C_{\mathrm{Si}} V_{C}$ center to be the only simple structure capable of producing the observed optical transitions and it was proposed that $C_{\mathrm{Si}} V_{C}$ forms through the reaction $V_{\mathrm{Si}}+C_{C} \rightarrow C_{\mathrm{Si}} V_{C}$ during the annealing process. The observation made in the neutron irradiated $n$-type $6 \mathrm{H}-\mathrm{SiC}$ materials that, the intensities of the deep levels $E_{1} / E_{2}$ and the $P 6 / P 7$ centers were small in the un-irradiated or the as-irradiated samples but increased after the $600{ }^{\circ} \mathrm{C}$ annealing could thus be possibly explained if $E_{1} / E_{2}$ and $P 6 / P 7$ originated from the same defect $C_{\mathrm{Si}} V_{C}$.

As the $E_{1} / E_{2}$ intensities keep on increasing in the range of annealing temperatures up to $500{ }^{\circ} \mathrm{C}$ and reach the maximum at this temperature, we would point out that if $C_{\mathrm{Si}} V_{C}$ is responsible for $E_{1} / E_{2}$ it is unlikely that these sites are all created from the mobility and annihilation of a $V_{\mathrm{Si}}$ since the silicon vacancy is known to be stable in the temperature range up to $\sim 700{ }^{\circ} \mathrm{C}$. For example, using the positron lifetime technique, Ling, Beling, and Fung ${ }^{23}$ have observed that $V_{\mathrm{Si}}$ related defect in $n$-type $6 \mathrm{H}-\mathrm{SiC}$ anneals only after $650{ }^{\circ} \mathrm{C}$ annealing. Moreover, Sörman et al. ${ }^{27}$ have noted the stability of photoluminescence (PL) lines associated with the isolated silicon vacancy, up to $750^{\circ} \mathrm{C}$. It is more likely that there exists another channel that the $C_{\mathrm{Si}} V_{C}$ defect could form through. Since the $V_{C}$ related defect is mobile in the temperature below $500{ }^{\circ} \mathrm{C}$ (see discussed on $E_{i}$ level above), one of the possible formation reactions is through the process $V_{C}+C_{\mathrm{Si}} \rightarrow C_{\mathrm{Si}} V_{C}$, since it is known that the carbon antisite has low formation energy, which is likely to be the most common native defect in as-grown $\mathrm{SiC}^{28}$ Such a formation is consistent with the observation that the decrease of the $E_{i}$ annealing curve coincides well with the increase of the $E_{1} / E_{2}$ intensities [Figs. 3 and 4(a)]. While looking promising, the identification of $E_{1} / E_{2}$ with $C_{\mathrm{Si}} V_{C}$ is not unambiguously proved and further investigations are certainly needed for further clarification.

\section{D. $Z_{1} / Z_{2}$ and $N E 3 / N E 4$ levels}

Earlier thermal annealing studies indicated that the $Z_{1} / Z_{2}$ centers persisted at annealing temperatures up to $1700{ }^{\circ} \mathrm{C},{ }^{2,3}$ in contradiction with the present study which shows the levels to have completely annealed out by $900^{\circ} \mathrm{C}$ and other recent results showing that the $Z_{1} / Z_{2}$ deep levels disappear at temperatures below $1000{ }^{\circ} \mathrm{C} .{ }^{6,7}$ The early study can be explained from the observation in the present study, 
that as the $Z_{1} / Z_{2}$ levels anneal so two new deep level centers (NE3 and $N E 4$ ) having very close ionization energies to those of $Z_{1} / Z_{2}$ are generated upon the $1600{ }^{\circ} \mathrm{C}$ annealing. It is thus possible that the deep levels termed $Z_{1} / Z_{2}$ reported stable up to $1700{ }^{\circ} \mathrm{C}$ in the earlier study are indeed the $N E 3 / N E 4$ annealing induced deep levels defects. To support this view we point out that under the same rate window settings the peak position temperatures of the $N E 3$ and $N E 4$ deep levels are about $40 \mathrm{~K}$ higher than those of the $Z_{1} / Z_{2}$ levels (Fig. 5), indicating that the capture cross sections for $N E 3 / N E 4$ defects are lower than those of the $Z_{1} / Z_{2}$ centers (as can also be seen from the Arrhenius plots of Fig. 6). Although cross sections can vary greatly for samples with different strain and with different modes of carrier scattering, the different cross sections indicate that the NE3/NE4 centers are either a modified form of the $Z_{1} / Z_{2}$ centers or are of a completely different structure. The fact that the $900{ }^{\circ} \mathrm{C}$ anneal completely removes $Z_{1} / Z_{2}$ [Fig. 3(c)] also supports the view that the structures responsible for these levels have been removed by annealing and thus that the NE3/NE4 levels are of a new origin.

The earlier study that suggested that $Z_{1} / Z_{2}$ was stable up to $1700{ }^{\circ} \mathrm{C}$ gave rise to the idea that the defect center could be $V_{\mathrm{Si}} V_{C}$. In view of the above observations that $Z_{1} / Z_{2}$ anneals at the much lower temperature range of 500$900^{\circ} \mathrm{C}$ and the fact that this annealing behavior parallels that of the isolated silicon vacancy $V_{\mathrm{Si}}$ as seen by positron lifetime spectroscopy ${ }^{23,24}$ and $\mathrm{PL}^{27}$ has led a number of workers to suggest that $Z_{1} / Z_{2}$ is produced by $V_{\mathrm{Si}} \cdot{ }^{25,26}$ Moreover, measuring the positron lifetime spectra of irradiated $6 \mathrm{H}-\mathrm{SiC}$ materials with monochromatic illumination, $V_{\mathrm{Si}}$ has been recently shown to have an ionization level at $0.6 \pm 0.1 \mathrm{eV}$ below the conduction band, which indeed coincides with that of $Z_{1} / Z_{2} \cdot{ }^{26}$ This identification can also explain the double peak nature of this level, with one peak coming from the hexagonal-site $h$ and the other from the quasicubic-sites $k_{1}$, $k_{2}$.

\section{E. NE1 and NE2}

The activation energies of the $N E 1$ and $N E 2$ levels found in the $1600{ }^{\circ} \mathrm{C}$ annealed samples are determined at $E_{C}-0.44$ and $0.53 \mathrm{eV}$. Their concentrations are found to be higher on samples annealed at a temperature of $1600^{\circ} \mathrm{C}$ than on those annealed at $1400{ }^{\circ} \mathrm{C}$ indicating that these peaks are indeed thermally induced. We noted that the activation energy of the $N E 1$ level is identical to that of $E_{1} / E_{2}$. However, as shown in Fig. 5, under the same rate window setting, the temperature position of the $N E 1$ peak maximum is shifted to higher temperature by $50 \mathrm{~K}$ indicating that $N E 1$ is a peak of different microstructural origin. This view is supported by the absence in $N E 1$ of the well known overlapping peak structure of $E_{1} / E_{2}$ which has been suggested to result from the same defect on inequivalent $6 \mathrm{H}-\mathrm{SiC}$ lattice sites. Therefore, these results make it seem unlikely that the $N E 1$ originates from the same defect centers causing $E_{1} / E_{2} \cdot{ }^{10} \mathrm{On}$ the other hand, evidence exists from two other studies that $N E 1$ and $N E 2$ are to be associated with postimplantation annealing induced deep level centers. First, Dalibor et al. ${ }^{4}$ have observed the electron traps labeled ID6 and ID7 (having activation energies of $0.40-0.43$ and $0.50-0.54 \mathrm{eV}$, respectively) in $n$-type $6 \mathrm{H}-\mathrm{SiC}$ samples implanted by vanadium and titanium followed by $30 \mathrm{~min} 1700^{\circ} \mathrm{C}$ annealing. Second, electron traps $B E 2$ and $B E 3$ with identical activation energies to those of $N E 1$ and $N E 2$ have also been observed in Be implanted $n$-type $6 \mathrm{H}-\mathrm{SiC}$ after annealing at $1600{ }^{\circ} \mathrm{C}^{29}$ Thus in summary, the close similarity of the activation energies of the $N E 1$ (and $N E 2$ ) deep levels observed in the present study with those of $I D 6 / B E 2$ (and $I D 7 / B E 3$ ) found in high temperature annealed ion implanted $n$-type $6 \mathrm{H}-\mathrm{SiC}$ materials (refer to Table II), made it reasonable to suggest that $N E 1$ is probably the same level as $I D 6 / B E 2$ and $N E 2$ the same level as $I D 7 / B E 3$.

It is also worth pointing out that $N E 1-N E 4$ can also be observed in the $1600{ }^{\circ} \mathrm{C}$ annealed un-irradiated sample, despite the fact that their intensities are much lower than those in the neutron-irradiated sample. As these four peaks are not found in the as-grown sample (DLTS measurement performed but not shown), this implies the observed NE1-NE4 defects are the products of the thermal annealing. As the neutron irradiation enhances the formation of these defects, it implies some of the neutron-irradiation induced defects are possibly involved in the reaction that leads to the formation of $N E 1-N E 4$.

\section{SUMMARY}

In summary, DLTS has been used to study deep level defects in $n$-type $6 \mathrm{H}-\mathrm{SiC}$ materials induced by neutron irradiation. Additional isochronal annealing has also been performed in order to characterize the induced defects. Deep levels at $E_{C}-0.23 \mathrm{eV}(E D 1), E_{C}-0.36 / 0.44 \mathrm{eV}\left(E_{1} / E_{2}\right)$, $E_{C}-0.50 \mathrm{eV}\left(E_{i}\right.$ or $\left.R D 5\right)$, and $E_{C}-0.62 / 0.68 \mathrm{eV}\left(Z_{1} / Z_{2}\right)$ have been identified and studied. $E D 1$ and $E_{i}$ were observed to anneal out at relatively low temperatures (below $350^{\circ} \mathrm{C}$ ). It has been suggested that the structure of $E_{i}$ is likely to be $V_{C}$ related. Unlike the electron irradiated material, but similar to $\mathrm{He}$ and deuterium implanted, the $E_{1} / E_{2}$ are found not to be the dominant peaks in as-neutron-irradiated DLTS spectra. The fact that the intensity of increased $E_{1} / E_{2}$ first increases with annealing temperature, reaching a maximum at $500-750{ }^{\circ} \mathrm{C}$ and then annealing out at $1400^{\circ} \mathrm{C}$, has been tentatively interpreted, together with other evidence, in terms of the $C_{\mathrm{Si}} V_{C}$ center. The $Z_{1} / Z_{2}$ levels were found to anneal out at temperatures below $900{ }^{\circ} \mathrm{C}$, while strongly suggesting that the $V_{\mathrm{Si}}$ defect for the responsible microstructure does not rule out other defect centers.

An important observation made in the present work has been that of the thermal generation of deep levels $N E 1-N E 4$ at annealing temperatures above $1400^{\circ} \mathrm{C}$. The evidence that we have given strongly suggests that these levels are not to be associated with either $E_{1} / E_{2}$ or $Z_{1} / Z_{2}$ but are indeed new defect levels happening to have very similar energy levels. While these new levels may be associated with microstructures very similar in some way to those responsible for $E_{1} / E_{2}$ or $Z_{1} / Z_{2}$, it is also possible that their origin could have no association with the origin of the $E_{1} / E_{2}$ or $Z_{1} / Z_{2}$ levels. It is too early to speculate on the origin of 
$N E 1-N E 4$, but it is hoped that the evidence given that these defects are indeed different than $E_{1} / E_{2}$ or $Z_{1} / Z_{2}$ will stimulate further research into their microscopic origin.

\section{ACKNOWLEDGMENTS}

The work described in this article is partially supported by a grant from the Research Grant Council of the Hong Kong Special Administrative Region, China (under Project Nos. 7085/01P, HKU1/00C, HKU7137/99P and HKU7103/ 02P) and the Hung Hing Ying Physical Science Research Fund. One of the authors (X.D.C) wishes to acknowledge his PDF support from HKU. M. G. also acknowledges support from the grant of National Nature Science of China (No. 60076010).

${ }^{1}$ H. Morkoç, S. Strite, G. B. Gao, M. E. Lin, B. Sverdlov, and M. Burns, J. Appl. Phys. 76, 1363 (1994).

${ }^{2}$ G. Pensl and W. J. Choyke, Physica B 185, 264 (1993).

${ }^{3}$ H. Zhang, G. Pensl, A. Dornen, and S. Leibenzeder, Journal of the Electrochemical Society, Extended Abstracts 89-2, 699 (1989).

${ }^{4}$ T. Dalibor, G. Pensl, H. Matsunami, T. Kimoto, W. J. Choyke, A. Schoener, and N. Nordell, Phys. Status Solidi A 162, 199 (1997).

${ }^{5}$ C. G. Hemmingsson, N. T. Son, O. Kordina, E. Janzén, and J. L. Lindström, J. Appl. Phys. 84, 704 (1998).

${ }^{6}$ M. Gong, S. Fung, C. D. Beling, and Z. You, J. Appl. Phys. 85, 7604 (1999).

${ }^{7}$ M. O. Aboelfotoh and J. P. Doyle, Phys. Rev. B 59, 10823 (1999).

${ }^{8}$ A. A. Lebedev, A. I. Veinger, D. V. Davydov, V. V. Kozlovski, N. S. Savkina, and A. M. Strel'chuk, J. Appl. Phys. 88, 6265 (2000).

${ }^{9}$ Th. Frank, G. Pensl, Song bai, R. P. Devaty, and W. J. Choyke, Mater. Sci. Forum 338-342, 753 (2000).
${ }^{10}$ M. Weidner, T. Frank, G. Pensl, A. Kawasuso, H. Itoh, and R. KrauseRehberg, Physica B 308-310, 633 (2001).

${ }^{11}$ H. Heissenstein, C. Peppermuller, and R. Helbig, J. Appl. Phys. 83, 7542 (1998)

${ }^{12}$ A. I. Veinger, A. G. Zabrodshi, G. A. Lomakina, and E. N. Mokhov, Sov. Phys. Solid State 28, 917 (1986).

${ }^{13}$ V. Nagesh, J. W. Farmer, R. F. Davis, and H. S. Kong, Radiat. Eff. Defects Solids 112, 77 (1990).

${ }^{14}$ V. Nagesh, J. W. Farmer, R. F. Davis, and H. S. Kong, Appl. Phys. Lett. 50, 1138 (1987).

${ }^{15}$ A. I. Veinger, A. A. Lepneva, G. A. Lomakina, E. N. Mokhov, and V. I. Sokolov, Sov. Phys. Semicond. 18, 1256 (1984).

${ }^{16}$ M. Okada, K. Atobe, M. Nakagawa, S. Kanazawa, I. Kanno, and I. Kimura, Nucl. Instrum. Methods Phys. Res. B 166, 167, 399 (2000).

${ }^{17}$ N. Nayashi, H. Watanabe, K. Sakai, K. Kuriyama, Y. Ikeda, H. Maekawa, and T. Miura, Mater. Sci. Forum 196-201, 1243 (1995).

${ }^{18}$ Th. Lingner, S. Greulich-Weber, and J. M. Spaeth, Phys. Rev. B 64, 245212 (2001).

${ }^{19}$ C. V. Reddy, S. Fung, and C. D. Beling, Rev. Sci. Instrum. 67, 257 (1996).

${ }^{20}$ D. V. Lang, J. Appl. Phys. 45, 3023 (1974).

${ }^{21}$ H. Itoh, A. Kawasuso, T. Ohshima, M. Yoshikawa, I. Nashiyama, S. Tanigawa, S. Misawa, H. Okumura, and Y. Yoshida, Phys. Status Solidi A 162, 173 (1997).

${ }^{22}$ N. T. Son, P. N. Hai, and E. Janzén, Phys. Rev. B 63, 201201 (2001).

${ }^{23}$ C. C. Ling, C. D. Beling, and S. Fung, Phys. Rev. B 62, 8016 (2000).

${ }^{24}$ A. Polity, S. Huth, and M. Lausmann, Phys. Rev. B 59, 10603 (1999).

${ }^{25}$ A. Kawasuso, F. Redmann, R. Krause-Rehberg, T. Frank, M. Weidner, G. Pensl, P. Sperr, and H. Itoh, J. Appl. Phys. 90, 3377 (2001).

${ }^{26}$ S. Arpiainen, K. Saarinen, P. Hautojärvi, L. Henry, M. F. Barthe, and C. Corbel, Phys. Rev. B 66, 075206 (2002).

${ }^{27}$ E. Sörman, N. T. Son, W. M. Chen, O. Kordina, C. Hallin, and E. Janzén, Phys. Rev. B 61, 2613 (2000).

${ }^{28}$ L. Torpo, S. Pöykkö, and R. M. Nieminen, Phys. Rev. B 57, 6243 (1997).

${ }^{29}$ X. D. Chen, S. Fung, C. D. Beling, M. Gong, T. Henkel, H. Tanoue, and N. Kobayashi, J. Appl. Phys. 88, 4558 (2000). 